\title{
Light-Weight, Self-Powered Sensor Based on Triboelectric Nanogenerator for Big Data Analytics in Sports
}

\author{
Xiaofei Ma ${ }^{1}$, Xuan Liu ${ }^{2}$, Xinxing $\mathrm{Li}^{3}$ and Yunfei Ma ${ }^{4,5, *}$ \\ 1 Physical Education Department, Northeastern University at Qinhuangdao, Qinhuangdao 066000, China; \\ maxiaofei7555@163.com \\ 2 Physical Education Centre, Xi'an Jiaotong-Liverpool University, Suzhou 215123, China; \\ liuxuanivan@gmail.com \\ 3 Institute of Sports Science, Department of Physical Education, Seoul National University, Seoul 08826, Korea; \\ shinsunglee2021@snu.ac.kr \\ 4 Parallel Robot and Mechatronic System Laboratory of Hebei Province, Yanshan University, \\ Qinhuangdao 066004, China \\ 5 Key Laboratory of Advanced Forging \& Stamping Technology and Science of Ministry of National Education, \\ Yanshan University, Qinhuangdao 066004, China \\ * Correspondence: mayunfei@ysu.edu.cn
}

Citation: Ma, X.; Liu, X.; Li, X.; Ma, Y. Light-Weight, Self-Powered Sensor Based on Triboelectric Nanogenerator for Big Data Analytics in Sports. Electronics 2021, 10, 2322. https:// doi.org/10.3390/electronics10192322

Academic Editor: Giovanni Dimauro

Received: 20 August 2021

Accepted: 17 September 2021

Published: 22 September 2021

Publisher's Note: MDPI stays neutral with regard to jurisdictional claims in published maps and institutional affiliations.

Copyright: (c) 2021 by the authors. Licensee MDPI, Basel, Switzerland. This article is an open access article distributed under the terms and conditions of the Creative Commons Attribution (CC BY) license (https:/ / creativecommons.org/licenses/by/ $4.0 /)$.

\begin{abstract}
With the rapid development of the Internet of Things (IoTs), big data analytics has been widely used in the sport field. In this paper, a light-weight, self-powered sensor based on a triboelectric nanogenerator for big data analytics in sports has been demonstrated. The weight of each sensing unit is $\sim 0.4 \mathrm{~g}$. The friction material consists of polyaniline (PANI) and polytetrafluoroethylene (PTFE). Based on the triboelectric nanogenerator (TENG), the device can convert small amounts of mechanical energy into the electrical signal, which contains information about the hitting position and hitting velocity of table tennis balls. By collecting data from daily table tennis training in real time, the personalized training program can be adjusted. A practical application has been exhibited for collecting table tennis information in real time and, according to these data, coaches can develop personalized training for an amateur to enhance the ability of hand control, which can improve their table tennis skills. This work opens up a new direction in intelligent athletic facilities and big data analytics.
\end{abstract}

Keywords: PANI; PTFE; TENG; big data analytics

\section{Introduction}

The Internet of Things (IoT) is a huge network integrated with sensors in order to interface with our daily lives through data exchanging [1-12]. Moreover, in recent years, much attention has been attracted to the capturing of physiological indexes by sensors in big data analytics in the field of sports [13-19]. This modern science and technology contributes to improve the performance of athletes [20-28]. However, a collection of big data relies on various sensors and normally needs an external power supply. Realizing the rapid expansion of the IoT, it is important to design a novel sensor which does not need a power source.

Nowadays, triboelectric nanogenerators (TENGs) have been regarded as a next generation energy harvesting system [29-40]. Based on the coupling effects of triboelectrification and electrostatic induction, TENGs can effectively convert mechanical energy to electricity. The electrical signal can be influenced by pressure and is supposed to be a self-powered pressure sensor. The whole sensing process does not need any power units. TENGs have the advantages of simplicity, high efficiency, low cost, and light weight [41,42]. Therefore, this technology can be utilized in IoT applications for athletic big data analytics [43,44].

In this paper, a light-weight, self-powered sensor has been demonstrated for athletic big data analytics in table tennis training. The friction materials are consisted of polyte- 
trafluoroethylene (PTFE) and polyaniline (PANI) because of the big gap of electronegativity between these two materials. In addition, the advantages of the sensor being both soft and light-weight are more fit for its integration into the table tennis bats. Based on the structure of $\mathrm{Cu} / \mathrm{PTFE}$ over the PANI/Cu, the self-powered sensor can harvest the energy from the hit of table tennis and output electric signals. The signal strength is dependent on the velocity of the table tennis. Integrated with triboelectric nanogenerator units, this sensor can collect the data of the hitting position and the hitting velocity of table tennis balls. The weight of each sensing unit is light and soft, which has no influence on the table tennis bats. With the velocity of the table tennis increasing to $7.3 \mathrm{~m} / \mathrm{s}$, the output voltage is up to $6.05 \mathrm{~V}$. Finally, a practical application has been exhibited for collecting table tennis information in real time. By collecting data from daily table tennis training, the differences between the athlete and the amateur can be clearly observed. Furthermore, coaches can develop personalized training for the amateur to enhance their ability of hand control, which can improve their table tennis skills. This work opens up a new direction in intelligent athletic facilities and big data analytics.

\section{Materials and Methods}

\subsection{Materials}

Copper film $(100 \mu \mathrm{m})$ was purchased from Taobao. The thickness of polytetrafluoroethylene (PTFE) film was $22 \mu \mathrm{m}$, purchased from Shanghai Pudi Packing Material Company Limited. Tetrachloromethane $(\geq 99.0 \%)$, aniline $(\geq 99.5 \%)$, ammonium persulfate (APS, $\geq 98.0 \%$ ), hydrochloric acid (36.0-38.0\%) were purchased from Sinopharm Chemical Reagent Co., Ltd. (Shanghai, China). Rubber, sponge, and wood were from table tennis bats. All the materials were used without any further purification.

\subsection{Fabrication of the Light-Weight Self-Powered Sensor}

Firstly, $\mathrm{Cu}$ film was evaporated on the surface of rubber and PTFE surface by electron beam evaporation, respectively. Then, an electrochemical polymerization method was used to synthesis PANI on the $\mathrm{Cu} /$ rubber. The polymerization solution was $0.1 \mathrm{~mol} \cdot \mathrm{L}^{-1}$ aniline and $0.2 \mathrm{~mol} \cdot \mathrm{L}^{-1} \mathrm{HCl}$ in $100 \mathrm{~mL}$ deionized water. During the electrochemical polymerization process, cyclic voltammetry mode was conducted between -1.5 and $1.5 \mathrm{~V}$ for 100 cycles. Another surface of PTFE film was polished by emery paper. Then, rubber/Cu/PANI film and PTFE/Cu film with the same size were fixed together. Some pieces of sponge were placed around the rubber/Cu/PANI film and another PTFE/Cu film was fixed on the sponge, where there was a gap between the rubber/Cu/PANI film and PTFE/Cu film. Finally, the sensing unit was packaged with wood and rubber.

\subsection{Characterization and Measurement}

The sensing unit was driven by a linear motor for measuring the performance. The electrical signal was collected by a soft platform, consisting of LabVIEW and a low-noise preamplifier (Stanford research System SR560). The morphology of the materials was studied by scanning electron microscopy (SEM, Hitachi s4800, Tokyo, Japan). The optical images metalloscope (TMM-900). The applied force was tested by a pressure sensor (MD3060 , purchased from Taobao). All the measurements were conducted at room temperature $\left(24{ }^{\circ} \mathrm{C}\right)$ with $25 \%$ relative humidity.

\section{Results}

The boom in the IoT has also changed the sport field due to the increased communication among the smart sensors. On the basis of big data analytics, such as exercise performance and physiological information, coaches can develop more effective personalized training programs. In table tennis, the hitting position and hitting manner of the table tennis balls can control the falling points and motion trajectories, which can influence the outcome of the competitions. As shown in Figure 1a, this device can actively transform the data of hitting positions and hitting strength. Through big data analytics, table tennis 
coaches can immediately correct wrong manners, and athletics can improve their sports performance as soon as possible. Figure $1 \mathrm{~b}$ shows the structure of this device and the many sensing units that are implanted in the table tennis bat. The inset shows the detailed structure of one single sensing unit. Figure 1c shows an optical image of one sensing unit on an electronic balance, the weight of which is $\sim 0.40 \mathrm{~g}$. The size of the sensor is $1.5 \mathrm{~cm} \times 1.5 \mathrm{~cm}$. The light-weight sensing units integrated within the table tennis bats have few influences, which can be ignored. Figure 1d shows an optical image of sponges from a table tennis bat and the inset shows the large view of the sponge. The thickness of the sponge is $\sim 2 \mathrm{~mm}$, similar to the sponge of the table tennis bat, and the porous and loose structure can act as a support between the rubber/Cu/PANI film and the PTFE/Cu film. Figures S1 and 1e show the SEM images of the PTFE film before and after the polishing process. After polishing, the surface of the PTFE film becomes rough. Figure 1f shows the SEM image of PANI. Figure S2 shows the Fourier Spectroscopy of PANI, of which the two characteristic peaks belong to the PANI. The particularly rough surface of the PANI film and PTFE film can enhance the process of friction.

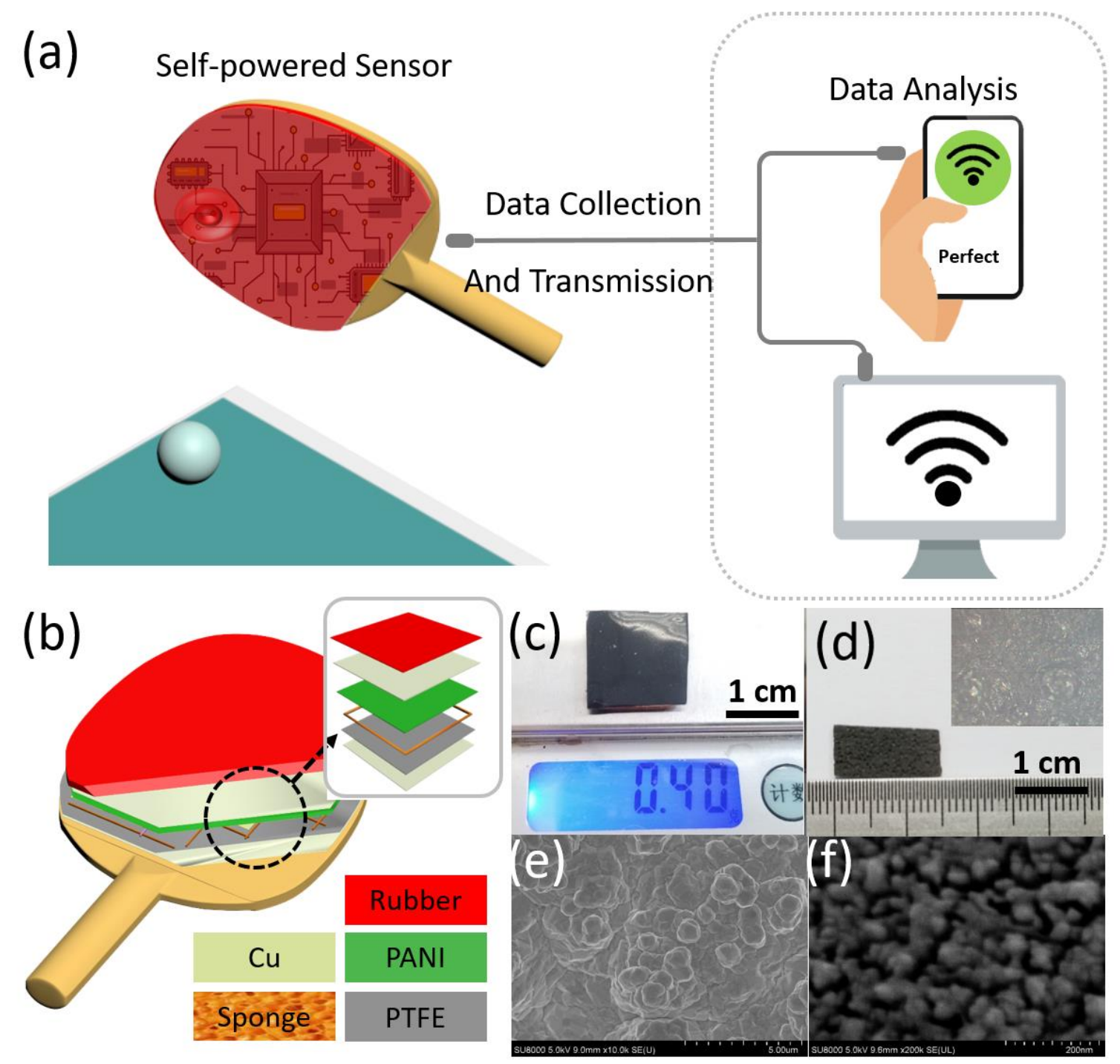

Figure 1. (a) The experimental design of the self-powered smart sensor for athletic big data analytics in table tennis training. (b) Device structure. The inset showing the structure of one single sensing unit. (c) Optical image of one sensing unit on an electronic balance. (d) Optical image of sponges from a table tennis bat. The inset showing the large view of metalloscope. (e) SEM image of PANI layer. (f) SEM image of PTFE film after polishing. 
Table 1 shows a comparison between other technologies, such as PENGs or electromagnetic sensors $[45,46]$. The device proposed by us has the advantages of weight, portability, and biocompatibility, which may be more suitable for athletic big data analytics.

Table 1. Comparison to other sensors.

\begin{tabular}{|c|c|c|c|c|c|c|}
\hline & Materials & Power Supply & Portability & Weight of Each Unit & Biocompatibility & Ref. \\
\hline PENG & PZT & Self-powered & Not portable & - & No & 1 \\
\hline $\begin{array}{l}\text { Electromagnetic } \\
\text { sensors }\end{array}$ & $\mathrm{Cu} / \mathrm{Fe}$ & External power & Not portable & Over $50 \mathrm{~g}$ & - & 2 \\
\hline This work & PTFE/PANI & Self-powered & Flexible & $0.4 \mathrm{~g}$ & Yes & - \\
\hline
\end{tabular}

Figure 2 shows the design of the device and the working mechanism. Figure 2a shows the measurement system. The table tennis ball is fixed on a support, which is driven by a linear motor (57BYGH250B, purchased from Taobao). The hitting velocity and hitting frequency can be controlled by programs. The electrodes are connected to the PANI and $\mathrm{Cu}$ layer, respectively. The aim was to simulate the process of the hitting position and hitting strength, and all the measurements were conducted at room temperature $\left(24{ }^{\circ} \mathrm{C}\right)$ with 25\% relative humidity. The Stanford Research System SR560 was used to collect the electrical signals from the sensing units. Based on the LabVIEW soft platform, the graphs can be observed on the computers or phones. The fundamental working mechanism of the device is based on the triboelectric effect, which is coupled with triboelectrification effect and electrostatic induction. Moreover, a theoretical model of one sensing unit (Figure 2b) can be built with the following $[47,48]$ :

$$
\begin{aligned}
Q_{\text {max }} & =\frac{\sigma S g}{d} \\
V_{\text {max }} & =\frac{d}{\varepsilon} Q
\end{aligned}
$$

where $Q_{\max }$ represents the maximum short circuit transferred charges and the $V_{\text {max }}$ represents the maximum output open circuit voltage, respectively. $\sigma$ represents the triboelectric charge density, $S$ represents the contact area of rubber $/ \mathrm{Cu} / \mathrm{PANI}$ film and PTFE/Cu film, $g$ represents the distance of the gap between the rubber $/ \mathrm{Cu} / \mathrm{PANI}$ film and PTFE/Cu film, $d$ represents the thickness of the PTFE film and $\varepsilon$ represents relative dielectric constant, respectively. A faster hitting velocity leads to the bigger contact area of rubber/Cu/PANI and PTFE/Cu film (S). Due to the difference in electronegativity, the surface of PTFE/Cu maintains lots of negative electrons and the surface of rubber/Cu/PANI maintains equal numbers of positive charges after the PTFE/ $\mathrm{u}$ film and rubber/Cu/PANI film contacts. The separation of the PTFE/Cu film and rubber/Cu/PANI film leads to the directional movement of electrons by electrostatic field. Therefore, the output triboelectric voltage increases with an increasing hitting velocity of the table tennis ball, and the hitting frequency does not influence the output triboelectric voltage. Figure 2c shows the working mechanism of one sensing unit. The signal is attributed to the triboelectrification effect. For the difference in the electronegativity of $\mathrm{Cu}$ and PTFE, the negative electrons on the surface of $\mathrm{Cu}$ film are maintained on the surface of the PTFE film after the $\mathrm{Cu}$ film contacts the PTFE film and the equal numbers of positive charges are left on the surface of $\mathrm{Cu}$ film. In the initial state, there is a gap between the $\mathrm{Cu}$ film and the PTFE/ $\mathrm{Cu}$ film. When the $\mathrm{Cu}$ film is hit by the table tennis ball, the gap decreases. The positive charges are driven by the electrostatic field through the external circuit. After hitting the sensing unit, the interval of the gap increases. A reversing electrical signal is induced by the electrostatic field through the external circuit. This sensing unit can convert mechanical energy into electrical energy, and the output of the triboelectric voltage is dependent on the hitting position and hitting strength. Figure $2 \mathrm{~d}$ shows the results of a finite element simulation in COMSOL of the 
model (Figure 2b); the simulating triboelectric voltage is up to $7.5 \mathrm{~V}$.
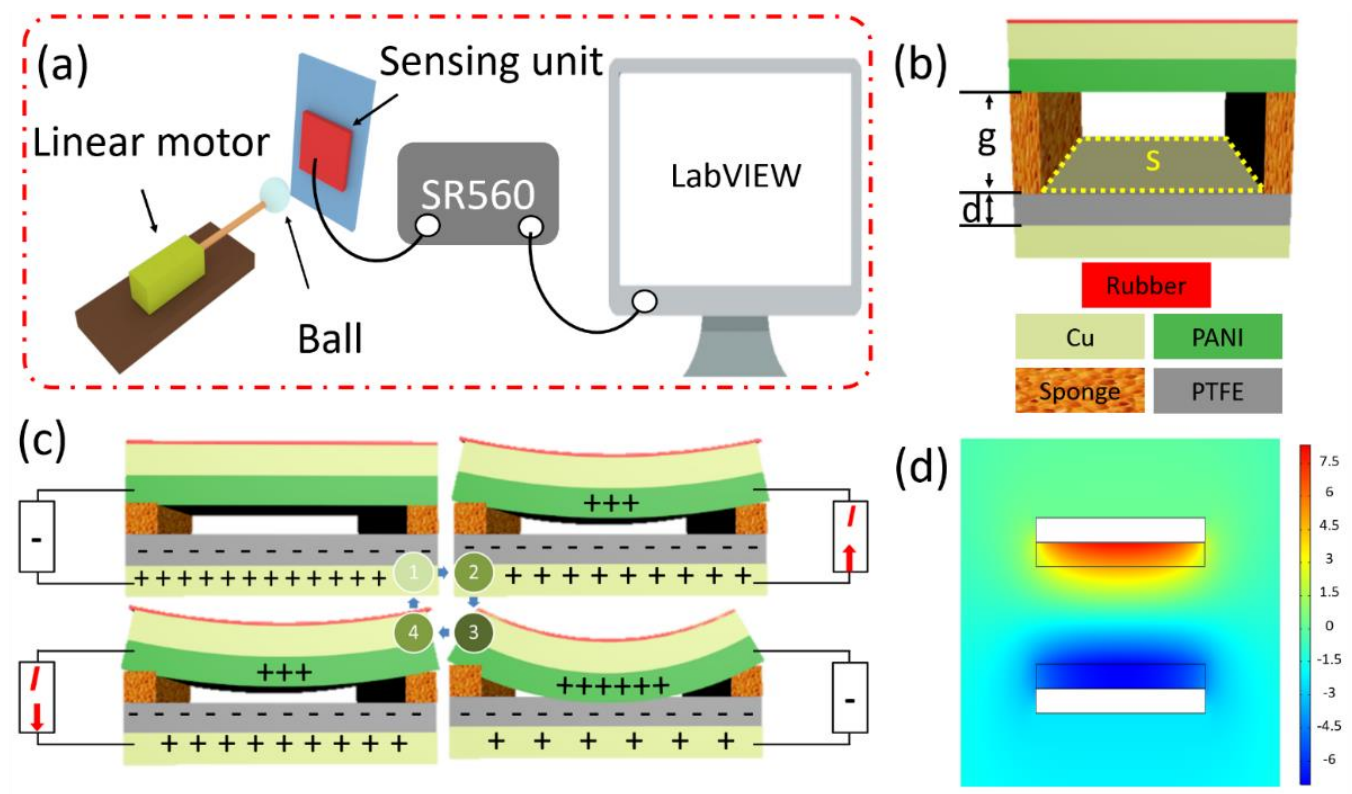

Figure 2. (a) The measurement system. (b) The model of one sensing unit. (c) The working mechanism. (d) Finite element simulation (COMOSL Multiphysics) of one single sensing unit.

Figure 3a shows the output against different friction materials. The triboelectric outputting voltage of the device with $\mathrm{Cu}$ and $\mathrm{Cu}$ friction is almost $\sim 0 \mathrm{~V}$. The reason for this is that there is no difference in electronegativity between the same materials. The triboelectric outputting voltage of the device with the $\mathrm{Cu}$ and PTFE film is $\sim 1.5 \mathrm{~V}$ and the output of the device with PANI and PTFE before polishing treatment is $\sim 1.3 \mathrm{~V}$, respectively. However, the output of the device with PANI and PTFE after polishing treatment is $\sim 6 \mathrm{~V}$, which can be attributed to the rough surface of contact area and huge difference in electronegativity between PTFE and PANI. Figure $3 b$ shows the schematic description of the charging circuit powered by this device. The type of diode used in the charging circuit is DB207. When the device outputs a positive electrical signal, charges are charged into the capacitor along the red route. Moreover, when the device outputs a negative electrical signal, charges are still charged into the capacitor along the other route. In both processes, all the charges are stored in the capacitor. If the capacitor is fully charged, the LED is lighted by turning on the switch. Figure $3 \mathrm{c}$ shows the voltage-time curve of the charging capacitor bythe device. After $20 \mathrm{~s}$, a $47 \mathrm{nF}$ capacitor can be charged to $4.5 \mathrm{~V}$ when the frequency is kept at $1 \mathrm{~Hz}$. Therefore, the device can also be regarded as a power source with which to supply electronics [49-51]. As shown in Figure 3d,e, an electronic calculator and an electronic watch can work after hitting the device for 30 s (Movies S1 and S2).

The performances of the device have been shown in Figure 4. Figure 4a shows the output triboelectric voltage against the different hitting velocities of table tennis ball $(1 \mathrm{~Hz})$. As shown in Figure 4a, the programmable system with a stepping motor and a sliding rail is controlled to improve the hitting speed of the table tennis ball, and the output triboelectric voltage increases. When the hitting velocity of the table tennis ball is $2,2.8,3.5,4.3,5,5.7$, $6.5,7.3 \mathrm{~m} / \mathrm{s}$, the output triboelectric voltage of the sensing unit is $0.20,0.70,1.35,2.10$, $3.0,3.95,5.30$, and $6.05 \mathrm{~V}$, respectively, and the red line is a linear fit. The linear fitting of Equation (3) is as follows:

$$
y=-3.4+1.6 x
$$

where $y$ represents the triboelectric voltage $(\mathrm{V})$ and $x$ represents the hitting velocity $(\mathrm{m} / \mathrm{s})$. The linearity is up to $\sim 0.99$. Figure $4 \mathrm{~b}$ shows the output triboelectric voltage against different hitting frequencies $(1,2,3,4$, and $5 \mathrm{~Hz})$. When the hitting velocity is $6.5 \mathrm{~m} / \mathrm{s}$, the hitting velocity is $6.5 \mathrm{~m} / \mathrm{s}$. Under this condition, the output triboelectric voltage almost 
maintains at a constant. When the hitting frequency of the table tennis ball is $1,2,3,4$, and $5 \mathrm{~Hz}$, the output triboelectric voltage of the sensing unit is $4.45,4.35,4.25,4.60$ and $4.50 \mathrm{~V}$, respectively. In low hitting frequencies, only the interval of each pulse decreases. Therefore, the hitting frequency has little influence on the output triboelectric voltage. The hitting angles are important in table tennis training. The triboelectric output triboelectric voltage against $30^{\circ}, 60^{\circ}$, and $90^{\circ}$ is shown in Figure $4 \mathrm{c}$, respectively. When the hitting angles of the table tennis ball are $30^{\circ}, 60^{\circ}$, and $90^{\circ}$, the outputted triboelectric voltage of the sensing unit is $3.32,4.98$, and $5.68 \mathrm{~V}$, respectively. When the hitting velocity remains unchanged, the velocity along the vertical direction increases with the hitting angle, which enhances the output triboelectric voltage. Figure $4 \mathrm{~d}$ shows the outputted triboelectric current of the sensing unit, which is $\sim 1.16 \mu \mathrm{A}$ under $1 \mathrm{~Hz}$ hitting frequency and $6.5 \mathrm{~m} / \mathrm{s}$ hitting velocity. Figure $4 \mathrm{e}$ shows the stability of one sensing unit. After many tests, the output is almost keeping at a constant $(\sim 6 \mathrm{~V})$. The excellent stability and high output power of the sensing unit shows the potential of future practical applications. The surface of a table tennis bat is divided into four parts: A, B, C, D, as shown in Figure 4f. Each of the parts are implanted with a sensing unit. When the table tennis ball hits the A part, the triboelectric signals in real time to the four sensing units that are shown in the inset of Figure $4 \mathrm{f}$. This result indicates the potential in collecting the data of hitting positions and hitting strength. These results agree with the above simulation (Figure $2 \mathrm{~d}$ ).
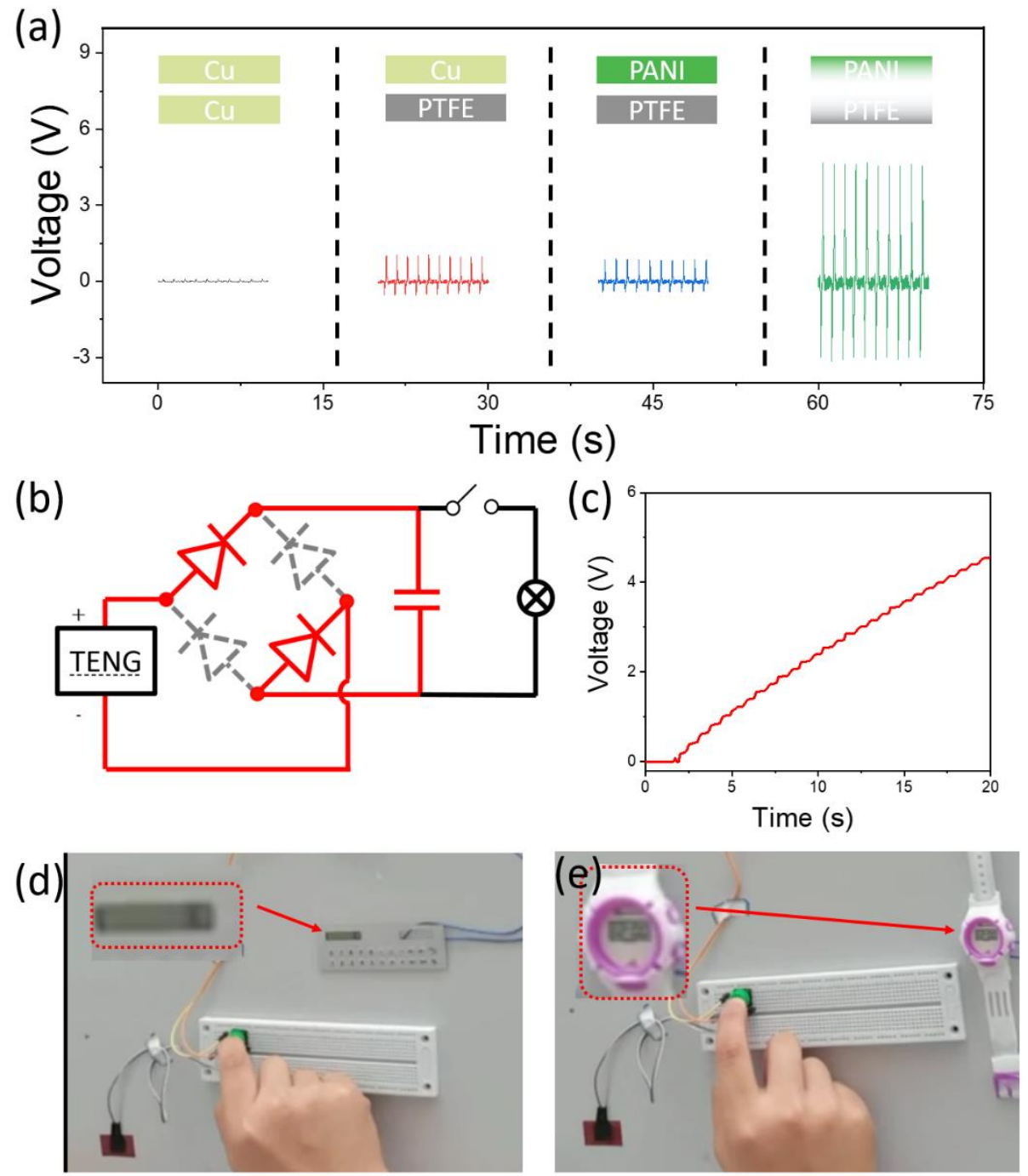

Figure 3. (a) Comparison of different friction materials. (b) The schematic description of charging circuit powered by TENG. (c) The voltage-time curve of the charging capacitor by TENG. (d) Powering for an electronic calculator. (e) Powering for an electronic watch. 

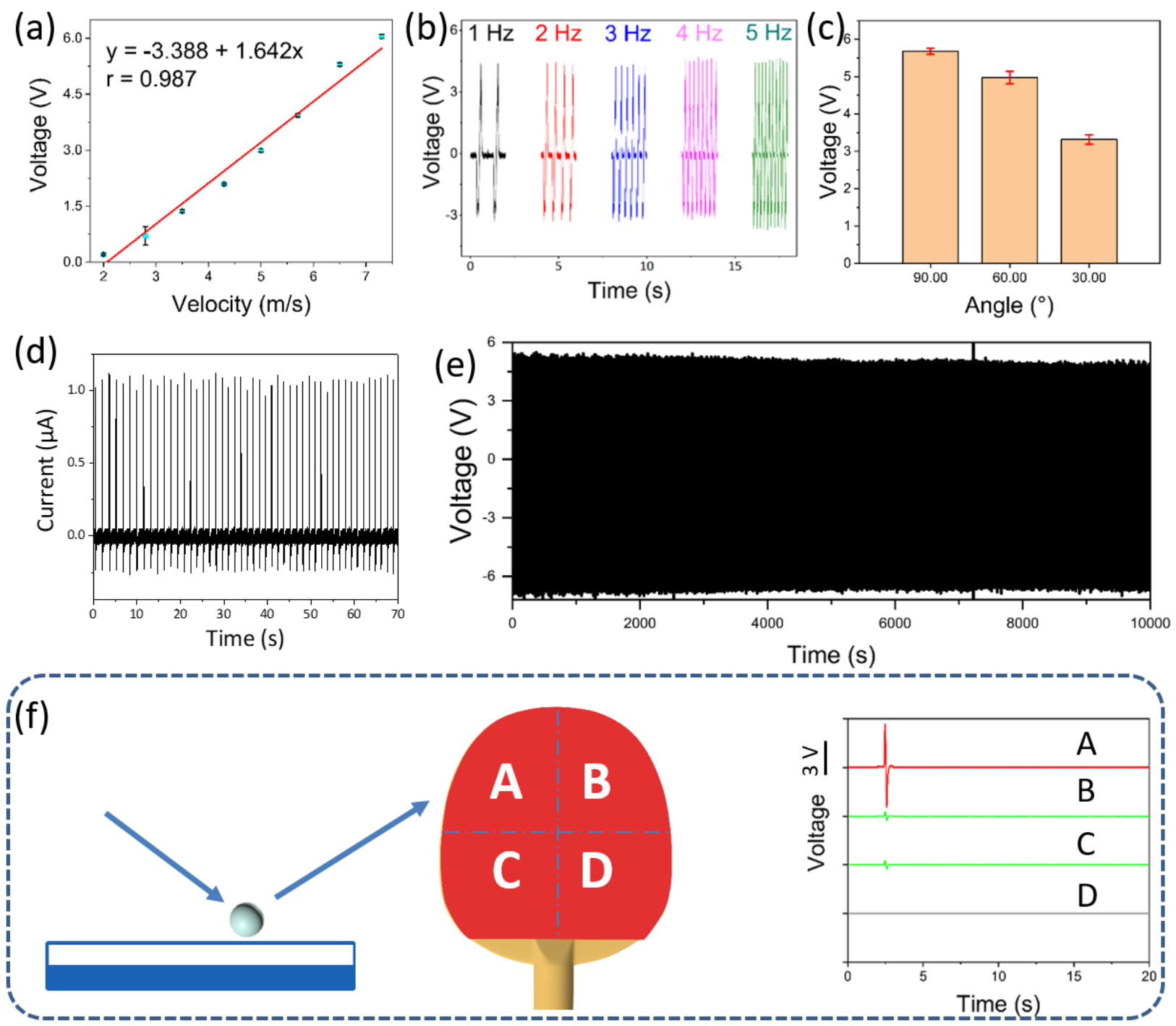

Figure 4. The performance of this self-powered smart bat: (a) The output triboelectric voltage against different hitting velocities. The red line showing the linear fit. (b) The output triboelectric voltage against different hitting frequencies. (c) The output triboelectric voltage against different hitting angles $\left(30^{\circ}, 60^{\circ}\right.$, and $90^{\circ}$, respectively). (d) The output current under $1 \mathrm{~Hz}$ and $5 \mathrm{~m} / \mathrm{s}$. (e) The stability of one sensing unit. (f) Table tennis hitting the device, integrating with four sensing units. The inset showing the triboelectric signals of four sensing units in real time.

Figure 5 shows the practical application of the device for athletic big data analytics in table tennis training. One sensing unit is on the surface of the bat (Figure 5a) and the sensing unit is collected and connected to a computer by a collector for the purposes of collecting the sensing signals. When a table tennis ball hits against the sensing unit, a PC can collect the electrical signal. The peak and the interval can reflect the hitting velocity and hitting frequency (Figure 5b). The high output can drive small electronics. As shown in Figure $5 c, d$, one sensing unit is connected to a LED. When the sensing unit is hit, the LED will be lighted (Movie S3). 

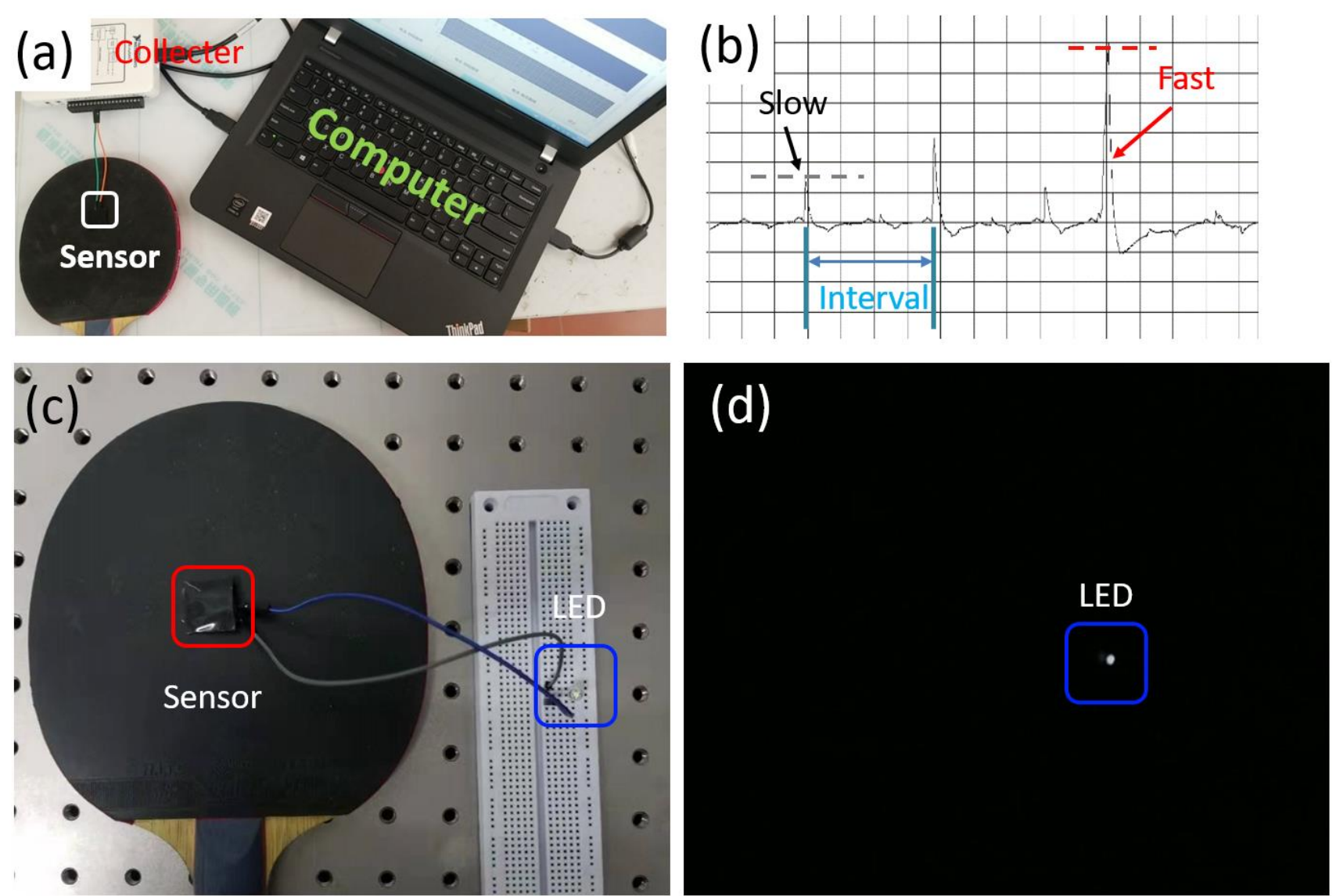

Figure 5. A practical application of the device: (a) One sensing unit on the surface of a table tennis bat. Computer can collect sensing data from the table tennis bat. (b) A screenshot from the computer of a table tennis ball's hitting. (c,d) The smart table tennis bat lighting the LED.

Here, two volunteers, an athlete and an amateur, were chosen for practical training data collecting. As shown in Figure 6, Two volunteers were asked to hit a table tennis ball 20 times in a row with the device. The sensing unit was attached to the middle of the bat and only the data of the table tennis balls that hit the sensing unit was collected. Figure $6 a, b$ shows the data from the two volunteers, respectively. Table 2 shows the detail data from the device. From the effective number of hits, the amateur is lower than the athlete, which implies that the amateur has more difficulty controlling the hitting point. Moreover, there are big differences between the athlete and the amateur among average interval of each hit, error of average interval, and Max-Min (average interval), which can imply that the athlete can set the pace better than the amateur. However, there is no significant difference in the outputting of voltage from the device. According to these data, coaches can develop personalized training for the amateur to enhance the ability of hand control, which can improve their table tennis skills.

In future, the device can integrate with lots of sensing units, which can collect training data in details. On the basis of big data analytics and physiological information, the coaches can develop more effective and personalized training programs to rapidly improve their athletes' sports performance. 

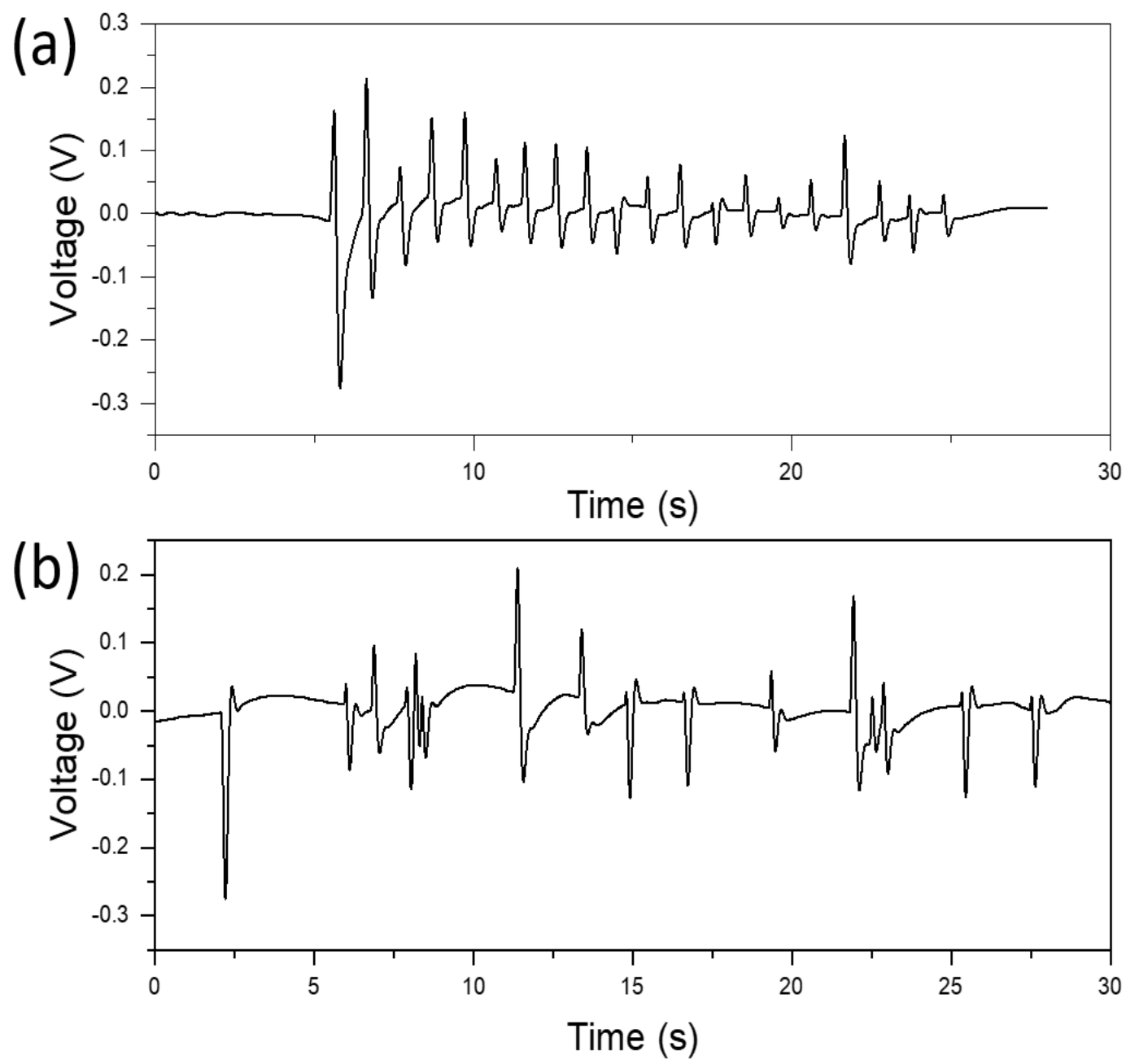

Figure 6. The training data from two people: (a) The data from an athlete. (b) The data from an amateur with less training.

Table 2. Training data.

\begin{tabular}{ccc}
\hline & Athlete & Amateur \\
\hline Total number of hits & 20 & 20 \\
Effective number of hits & 20 & 13 \\
Total time of hits & $20 \mathrm{~s}$ & $25 \mathrm{~s}$ \\
Average interval of each hit & $1.01 \mathrm{~s}$ & $2.12 \mathrm{~s}$ \\
Error of average interval & 0.01 & 0.99 \\
Max-Min (average interval) & $0.58 \mathrm{~s}$ & $2.96 \mathrm{~s}$ \\
Average voltage of each hit & $0.09 \mathrm{~V}$ & $0.11 \mathrm{~V}$ \\
Error of average voltage & 0.004 & 0.003 \\
Max-Min (average voltage) & $0.19 \mathrm{~V}$ & $0.25 \mathrm{~V}$ \\
\hline
\end{tabular}

\section{Conclusions}

In summary, a light-weight and flexible self-powered sensor for athletic big data analytics in table tennis training has been demonstrated. Based on the triboelectric effect, this device can output a triboelectric signal containing the hit frequency and the hit velocity of table tennis balls. The whole process does not need any external power units and the electrical output can power some small electronics (e.g., electronic calculators and electronic watches). Some disadvantages can be found by the self-powered sensor, and the personalized training process can be adjusted via the data to effectively improve the sports performance of the athletes. A practical application shows its future potential in the sports 
field. This work can provoke a new direction in intelligent athletic facilities and big data analytics.

Supplementary Materials: The following are available online at https:/ /www.mdpi.com/article/ 10.3390/electronics10192322/s1, Figure S1: SEM image of PTFE film before polishing, Figure S2: Fourier Spectroscopy of PANI, Movie S1: Powering for an electronic calculator. Movie S2: Powering for an electronic watch. Movie S3: The self-powered smart table tennis bat lighting the LED.

Author Contributions: Conceptualization, X.M. and Y.M.; methodology, X.M. and X.L. (Xinxing Li); software, X.M. and X.L. (Xinxing Li); validation, Y.M.; formal analysis, X.M. and X.L. (Xuan Liu); investigation, X.M. and X.L. (Xuan Liu); resources, Y.M.; data curation, Y.M.; writing-original draft preparation, X.M.; writing_review and editing, X.M. and Y.M.; visualization, X.M. and Y.M.; supervision, Y.M.; project administration, Y.M.; funding acquisition, Y.M. All authors have read and agreed to the published version of the manuscript.

Funding: This research was funded by Research and Practice Project of Teaching Reform for Higher Education Institutions in Hebei Province of China for Research and practice of table tennis project teaching in Colleges and Universities Based on "Outcome-based Education (OBE)" teaching concept, grant number 2018GJJG426.

Data Availability Statement: Data is contained within the article or supplementary material.

Conflicts of Interest: The authors declare no conflict of interest.

\section{References}

1. Augustin, A.; Yi, J.; Clausen, T.; Townsley, W.M. A Study of LoRa: Long Range \& Low Power Networks for the Internet of Things. Sensors 2016, 16, 1466.

2. Bandodkar, A.J.; Jeerapan, I.; Wang, J. Wearable Chemical Sensors: Present Challenges and Future Prospects. ACS Sens. 2016, 1, 464-482. [CrossRef]

3. Han, S.T.; Peng, H.; Sun, Q.; Venkatesh, S.; Chung, K.S.; Lau, S.C.; Zhou, Y.; Roy, V.A.L. An Overview of the Development of Flexible Sensors. Adv. Mater. 2017, 29, 1700375. [CrossRef]

4. Khan, Y.; Ostfeld, A.E.; Lochner, C.M.; Pierre, A.; Arias, A.C. Thermoelectric Polymers and their Elastic Aerogels. Adv. Mater. 2016, 28, 4373-4395. [CrossRef]

5. Singh, E.; Meyyappan, M.; Nalwa, H.S. Flexible Graphene-Based Wearable Gas and Chemical Sensors. ACS Appl. Mater. Interfaces 2017, 9, 34544-34586. [CrossRef]

6. Shakerighadi, B.; Anvari-Moghaddam, A.; Vasquez, J.C.; Guerrero, J.M. Internet of Things for Modern Energy Systems: State-ofthe-Art, Challenges, and Open Issues. Energies 2018, 11, 1252. [CrossRef]

7. Talari, S.; Shafie-khah, M.; Siano, P.; Loia, V.; Tommasetti, A.; Catalao, J.P.S. A Review of Smart Cities Based on the Internet of Things Concept. Energies 2017, 10, 421. [CrossRef]

8. Wang, Z.L. On Maxwell's displacement current for energy and sensors: The origin of nanogenerators. Mater. Today 2017, 20, 74-82. [CrossRef]

9. Xu, Q.H.; Fang, Y.S.; Jing, B.Q.S.; Hu, N.; Lin, K.; Pan, Y.F.; Xu, L.; Gao, H.Q.; Yuan, M.; Chu, L.; et al. A portable triboelectric spirometer for wireless pulmonary function monitoring. Biosens. Bioelectron. 2021, 187, 113329. [CrossRef]

10. Fang, Y.T.; Zhai, S.B.; Chu, L.; Zhong, J.S. Advances in Halide Perovskite Memristor from Lead-Based to Lead-Free Materials. ACS Appl. Mater. Interfaces 2021, 13, 17141-17157. [CrossRef] [PubMed]

11. Luan, R.F.; An, H.; Chen, C.; Xue, Y.; Guo, A.L.; Chu, L.; Ahmad, W.; Li, X.A. Stable Flexible Piezoresistive Sensors with Viscoelastic Ni Nanowires-PDMS Composites and Ni Foam Electrodes. Z. Anorg. Allg. Chem. 2021, 647, 1031-1037. [CrossRef]

12. Liu, L.Q.; Ju, W.; Li, Y.T.; He, X.M.; Zhang, H.G.; Chu, L. Tunable Photoluminescence of ZnO Nanowire Arrays via Native Defects. J. Nanoelectron. Optoelectron. 2020, 15, 394-397. [CrossRef]

13. Mao, Y.; Ba, N.; Gao, X.; Wang, Z.; Shen, M.; Liu, B.; Li, B.; Ma, X.; Chen, S. Self-Powered Wearable Sweat-Lactate Analyzer for Scheduling Training of Boat Race. J. Nanoelectron. Optoelectron. 2020, 15, 212-218. [CrossRef]

14. Mao, Y.; Shen, M.; Liu, B.; Xing, L.; Chen, S.; Xue, X. Self-Powered Piezoelectric-Biosensing Textiles for the Physiological Monitoring and Time-Motion Analysis of Individual Sports. Sensors 2019, 19, 3310. [CrossRef] [PubMed]

15. Mao, Y.; Yue, W.; Zhao, T.; Shen, M.; Liu, B.; Chen, S. A Self-Powered Biosensor for Monitoring Maximal Lactate Steady State in Sport Training. Biosensors 2020, 10, 75. [CrossRef] [PubMed]

16. Luo, J.J.; Wang, Z.M.; Xu, L.; Wang, A.C.; Han, K.; Jiang, T.; Lai, Q.S.; Bai, Y.; Tang, W.; Fan, F.R.; et al. Flexible and durable wood-based triboelectric nanogenerators for self-powered sensing in athletic big data analytics. Nat. Commun. 2019, $11,5147$. [CrossRef]

17. Kuang, S.Y.; Suo, X.C.; Song, P.Y.; Luo, J.J. Instantaneous Self-Powered Sensing System Based on Planar-Structured Rotary Triboelectric Nanogenerator. Sensors 2021, 21, 3741. [CrossRef] [PubMed] 
18. Mao, Y.; Zhang, W.; Wang, Y.; Guan, R.; Liu, B.; Wang, X.; Sun, Z.; Xing, L.; Chen, S.; Xue, X. Self-Powered Wearable Athletics Monitoring Nanodevice Based on ZnO Nanowire Piezoelectric-Biosensing Unit Arrays. Sci. Adv. Mater. 2019, 11, $351-359$. [CrossRef]

19. Zhao, T.M.; Wang, Q.; Du, A. Self-Powered Flexible Sour Sensor for Detecting Ascorbic Acid Concentration Based on Triboelectrification/Enzymatic-Reaction Coupling Effect. Sensors 2021, 21, 373. [CrossRef]

20. Luo, Y.; Zhao, T.M.; Dai, Y.T.; Li, Q.; Fu, H.Y. Flexible nanosensors for non-invasive creatinine detection based on triboelectric nanogenerator and enzymatic reaction. Sens. Actuators A Phys. 2021, 324, 112684. [CrossRef]

21. Zhang, W.L.H.; Guan, H.Y.; Zhong, T.Y.; Zhao, T.M.; Xing, L.L.; Xue, X.Y. Wearable Battery-Free Perspiration Analyzing Sites Based on Sweat Flowing on ZnO Nanoarrays. Nano-Micro Lett. 2020, 12, 105. [CrossRef]

22. He, H.X.; Zhao, T.M.; Guan, H.Y.; Zhong, T.Y.; Zeng, H.; Xing, L.L.; Zhang, Y.; Xue, X.Y. A water-evaporation-induced self-charging hybrid power unit for application in the Internet of Things. Sci. Bull. 2019, 64, 1049-1417. [CrossRef]

23. Zhao, T.M.; Zheng, C.W.; He, H.X.; Guan, H.Y.; Zhong, T.Y.; Xing, L.L.; Xue, X.Y. A self-powered biosensing electronic-skin for real-time sweat Ca2+ detection and wireless data transmission. Smart Mater. Struct. 2019, 28, 085015. [CrossRef]

24. Bermon, S.; Hirschberg, A.L.; Kowalski, J.; Eklund, E. Serum androgen levels are positively correlated with athletic performance and competition results in elite female athletes. Br. J. Sport. Med. 2018, 52, 1531-1532. [CrossRef]

25. Casa, D.J.; Cheuvront, S.N.; Galloway, S.D.; Shirreffs, S.M. Fluid Needs for Training, Competition, and Recovery in Track-and-Field Athletes. Int. J. Sport Nutr. Exerc. Metab. 2019, 29, 175-180. [CrossRef]

26. Hobara, H.; Saito, S.; Hashizume, S.; Sakata, H.; Kobayashi, Y. Individual Step Characteristics During Sprinting in Unilateral Transtibial Amputees. J. Appl. Biomech. 2018, 34, 509-513. [CrossRef]

27. Meier, H.E.; Jetzke, M.; Nagm, A.; von Uechtritz, C. Superior Sporting Performance in Athletics: Determinants and Sustainability. Soc. Sci. Quart. 2019, 100, 1862-1898. [CrossRef]

28. Wayne, N.L.; Miller, G.A. Impact of gender, organized athletics, and video gaming on driving skills in novice drivers. PLoS ONE 2018, 13, e0190885. [CrossRef] [PubMed]

29. Zhao, T.M.; Li, J.L.; Zeng, H.; Fu, Y.M.; He, H.X.; Xing, L.L.; Zhang, Y.; Xue, X.Y. Self-powered wearable sensing-textiles for real-time detecting environmental atmosphere and body motion based on surface-triboelectric coupling effect. Nanotechnology 2018, 29, 075501. [CrossRef] [PubMed]

30. Zhao, T.M.; Han, Y.C.; Qin, L.N.; Guan, H.Y.; Xing, L.L.; Li, X.J.; Xue, X.Y.; Li, G.L.; Zhan, Y. Bidirectional modulation of neural plasticity by self-powered neural stimulation. Nano Energy 2021, 85, 106006. [CrossRef]

31. Chen, J.; Zhu, G.; Yang, W.; Jing, Q.; Bai, P.; Yang, Y.; Hou, T.C.; Wang, Z.L. Harmonic-Resonator-Based Triboelectric Nanogenerator as a Sustainable Power Source and a Self-Powered Active Vibration Sensor. Adv. Mater. 2013, 25, 6094-6099. [CrossRef]

32. Cheng, P.; Guo, H.; Wen, Z.; Zhang, C.; Yin, X.; Li, X.; Liu, D.; Song, W.; Sun, X.; Wang, J.; et al. Largely enhanced triboelectric nanogenerator for efficient harvesting of water wave energy by soft contacted structure. Nano Energy 2019, 57, 432-439. [CrossRef]

33. Fan, F.R.; Tang, W.; Wang, Z.L. Flexible Nanogenerators for Energy Harvesting and Self-Powered Electronics. Adv. Mater. 2016, 28, 4283-4305. [CrossRef]

34. Lin, Z.H.; Cheng, G.; Lee, S.; Pradel, K.C.; Wang, Z.L. Harvesting Water Drop Energy by a Sequential Contact-Electrification and Electrostatic-Induction Process. Adv. Mater. 2014, 26, 4690-4696. [CrossRef]

35. Liu, W.L.; Wang, Z.; Wang, G.; Liu, G.; Chen, J.; Pu, X.; Xi, Y.; Wang, X.; Guo, H.; Hu, C.; et al. Integrated charge excitation triboelectric nanogenerator. Nat. Commun. 2019, 10, 1426. [CrossRef]

36. Nie, J.H.; Wang, Z.M.; Ren, Z.W.; Li, S.Y.; Chen, X.Y.; Wang, Z.L. Power generation from the interaction of a liquid droplet and a liquid membrane. Nat. Commun. 2019, 10, 2264. [CrossRef]

37. Xu, L.; Jiang, T.; Lin, P.; Shao, J.J.; He, C.; Zhong, W.; Chen, X.Y.; Wang, Z.L. Coupled Triboelectric Nanogenerator Networks for Efficient Water Wave Energy Harvesting. ACS Nano 2018, 12, 1849-1858. [CrossRef] [PubMed]

38. Heo, D.; Chung, J.; Shin, G.; Seok, M.; Lee, C.; Lee, S. Yo-Yo Inspired Triboelectric Nanogenerator. Energies 2021, 14, 1798. [CrossRef]

39. Chen, C.Y.; Zhang, L.; Ding, W.B.; Chen, L.J.; Liu, J.K.; Du, Z.Q.; Yu, W.D. Woven Fabric Triboelectric Nanogenerator for Biomotion Energy Harvesting and as Self-Powered Gait-Recognizing Socks. Energies 2020, 13, 4119. [CrossRef]

40. Zhu, G.; Peng, B.; Chen, J.; Jing, Q.; Wang, Z.L. Interconnected carbon nanotube/graphene nanosphere scaffolds as free-standing paper electrode for high-rate and ultra-stable lithium-sulfur batteries. Nano Energy 2015, 14, 126-138. [CrossRef]

41. Pu, X.; Li, L.X.; Song, H.Q.; Du, C.H.; Zhao, Z.F.; Jiang, C.Y.; Cao, G.Z.; Hu, W.G.; Wang, Z.L. A Self-Charging Power Unit by Integration of a Textile Triboelectric Nanogenerator and a Flexible Lithium-Ion Battery for Wearable Electronics. Adv. Mater. 2015, 27, 2472-2478. [CrossRef]

42. Wang, S.H.; Lin, L.; Wang, Z.L. Triboelectric nanogenerators as self-powered active sensors. Nano Energy 2015, 11, 436-462. [CrossRef]

43. Lin, Z.M.; Wu, Z.Y.; Zhang, B.B.; Wang, Y.C.; Guo, H.Y.; Liu, G.L.; Chen, C.Y.; Chen, Y.L.; Yang, J.; Wang, Z.L. A triboelectric nanogenerator-based smart insole for multifunctional gait monitoring. Adv. Mater. Technol. 2018, 4, 1800360. [CrossRef]

44. Massimo, M.; Luca, F.; Francesco, G.; Massimo, D.V. Conformal, ultra-thin skin-contact-actuated hybrid piezo/triboelectric wearable sensor based on AIN and parylene-encapsulated elastomeric blend. Adv. Funct. Mater. 2021, $31,2101047$. 
45. Tian, G.; Deng, W.L.; Gao, Y.Y.; Xiong, D.; Yan, C.; He, X.B.; Yang, T.; Jin, L.; Chu, X.; Zhang, H.T.; et al. Rich lamellar crystal baklava-structured PZT/PVDF piezoelectric sensor toward individual table tennis training. Nano Energy 2019, 59, 574-581. [CrossRef]

46. Tao, W.J.; Liu, T.; Zheng, R.C.; Feng, H.T. Gait Analysis Using Wearable Sensors. Sensors 2012, 12, 2255-2283. [CrossRef] [PubMed]

47. Niu, S.; Liu, Y.; Chen, X.; Wang, S.; Zhou, Y.; Lin, L.; Xie, Y.; Wang, Z.L. Theory of freestanding triboelectric-layer-based nanogenerators. Nano Energy 2015, 12, 760-774. [CrossRef]

48. Liu, Y.; Niu, S.; Wang, Z.L. Theory of tribotronics. Adv. Electron. Mater. 2015, 1, 1500124. [CrossRef]

49. Zhai, C.; Chou, X.J.; He, J.; Song, L.L.; Zhang, Z.X.; Wen, T.; Tian, Z.M.; Chen, X.; Zhang, W.D.; Niu, Z.C.; et al. An electrostatic discharge based needle-to-needle booster for dramatic performance enhancement of triboelectric nanogenerators. Appl. Energy 2018, 231, 1346-1353. [CrossRef]

50. Wu, Z.Y.; Wang, P.; Zhang, B.B.; Guo, H.Y.; Chen, C.Y.; Lin, Z.M.; Cao, X.; Wang, Z.L. Highly durable and easily integrable triboelectric foam for active sensing and energy harvesting applications. Adv. Mater. Technol. 2021, 6, 2000737. [CrossRef]

51. Massimo, M.; Luca, F.; Francesco, G.; Massimo, D.V. Multifunctional sub-100 $\mu \mathrm{m}$ thickness flexible piezo/triboelectric hybrid water energy harvester based on biocompatible AIN and soft parylene C-PDMS-Ecoflex ${ }^{\mathrm{TM}}$. Nano Energy 2021, 83, 105811. 